\title{
Rationale for, Initiation and Titration of the Basal Insulin/GLP-1RA Fixed-Ratio Combination Products, IDegLira and IGlarLixi, for the Management of Type 2 Diabetes
}

Virginia Valentine $\cdot$ Jennifer Goldman · Jay H. Shubrook

Received: April 27, 2017 / Published online: July 18, 2017

(C) The Author(s) 2017. This article is an open access publication

\section{ABSTRACT}

Type 2 diabetes (T2D) is a progressive disease affecting glucose regulation and a major cause of morbidity and mortality globally. Many patients are not escalated up the treatment ladder appropriately despite failing to achieve glycemic control, with barriers such as fear of hypoglycemia, weight gain, and treatment burden recognized as factors. Exogenous basal insulin is titrated to address control of fasting plasma glucose and may preserve residual $\beta$-cell function, thus promoting a greater endogenous prandial insulin response. Native glucagon-like peptide-1 (GLP-1) is a peptide hormone secreted by the gut in response to nutrient ingestion; it increases insulin secretion, inhibits glucagon secretion,

Enhanced content To view enhanced content go to http://www.medengine.com/Redeem/3ED8F0606CD 6D7BF.

Electronic supplementary material The online version of this article (doi:10.1007/s13300-017-0287-y) contains supplementary material, which is available to authorized users.

V. Valentine $(\bowtie)$

Health-Scripts, Albuquerque, NM, USA

e-mail: vv@diabetestalk.com

J. Goldman

MCPHS University, Boston, MA, USA

J. H. Shubrook

Touro University California, Vallejo, CA, USA and prolongs gastric emptying, thereby lowering overall food intake. As its glucose-lowering action is glucose dependent, a GLP-1 receptor agonist (GLP-1RA) achieves these benefits with a lower risk of hypoglycemia compared with other diabetes therapies. Two products, an insulin degludec/liraglutide combination (IDegLira) and an insulin glargine/lixisenatide combination (IGlarLixi), were approved for use in adults with T2D by the US Food and Drug Administration in 2016. The efficacy and safety of these two basal insulin/GLP-1RA combination products were studied in the DUAL program (NCTs 01336023, 01392573, 01676116, 01618162, 01952145, and 02298192) and the LixiLan program (NCTs 02058160 and 02058147). Compared with basal insulin, insulin/GLP-1RA fixed-ratio combinations are superior at reducing $\mathrm{HbA}_{1 \mathrm{c}}$ with weight neutrality or weight loss rather than weight gain, as well as reduced hypoglycemia rates, and reduced insulin-dose requirement with IDegLira. A combination of different medications may often be required to achieve glycemic control, and fixed-ratio combination products allow such therapies to be given in simple regimens. Clinical trial data for these products highlight the great potential of these agents, not merely their efficacy and safety but also their ease of use and decreased injection burden for patients.

Keywords: GLP-1RA; $\mathrm{HbA}_{1 \mathrm{c}}$; Insulin; IGlarLixi; IDegLira; Type 2 diabetes 


\section{INTRODUCTION}

Type 2 diabetes (T2D) is a progressive multiorgan disease [1-3] that accounts for approximately $90 \%$ of all cases of diabetes; hence, it is a major cause of morbidity and mortality in both high-income and developing countries [4, 5]. T2D is a substantial health-economic burden in the Western world, with over $11 \%$ of total global healthcare expenditure attributed to diabetes (types 1 and 2) and one in five US healthcare dollars spent on caring for a person with diabetes $[5,6]$. Effective therapies that can improve the health of diabetes patients and reduce the healthcare cost to society are therefore required.

One regimen that has increased in popularity in recent years, because of the complementary actions of its components, is the combination of a basal insulin and glucagon-like peptide-1 (GLP-1) receptor agonist (GLP-1RA). Although this is an effective strategy, it requires multiple injections, which has led to the development of fixed-ratio combination products that require only one injection per day and so could simplify treatment. Our review considers the rationale for such products and the practicalities of initiating and using them for optimal effect in the clinical setting.

This article is based on previously conducted studies and does not involve any new studies of human or animal subjects performed by any of the authors. Studies were identified by searching PubMed and abstracts accepted by the American Diabetes Association (ADA), using the names of the combination products and their mono-components as search terms.

\section{RATIONALE FOR BASAL INSULIN + GLP-1RA COMBINATION THERAPIES}

\section{T2D Treatment Issues}

The main features of $\mathrm{T} 2 \mathrm{D}$ are declining $\beta$-cell function, global insulin resistance, and loss of the prandial insulin response with a corresponding lack of suppression of postprandial glucagon release [2]. By the time of diagnosis, $\beta$-cell function may have decreased by $50 \%$, and patients with the greatest disease progression before diagnosis may have lost over $80 \%$ of their $\beta$-cell function [7-9]. The rate of progression of $\beta$-cell failure defines the rate of progression of T2D [8], so interventions must be intensified accordingly in a timely manner; hence, patients rarely remain on their initial therapy regimen. Timely intensification of treatment helps patients to maintain glycemic control, which is easier than trying to gain or regain control. This is important because a reduction in glycated hemoglobin $\left(\mathrm{HbA}_{1 \mathrm{c}}\right)$ is associated with a corresponding reduced risk of both microvascular and macrovascular complications [2, 10]. Even when therapy is intensified, glycemic control can be lost over time because of the progressive nature of the disease. Less than $30 \%$ of adults with $\mathrm{T} 2 \mathrm{D}$ reach and maintain $\mathrm{HbA}_{1 \mathrm{c}}$ at less than $7.0 \%$ (less than $53 \mathrm{mmol} / \mathrm{mol}$ ) within 3 years of being started on basal insulin [11], and in one study, $57.6 \%$ of those who achieved their $\mathrm{HbA}_{1 \mathrm{c}}$ goal did not sustain it [12].

In the past, when basal insulin alone was insufficient to maintain glycemic control, the only effective intensification option for addressing postprandial glucose (PPG) control was to add mealtime bolus insulin, or switch to premixed insulin products. Control of PPG is key because postprandial hyperglycemia contributes to $\mathrm{HbA}_{1 \mathrm{c}}$, especially at lower $\mathrm{HbA}_{1 \mathrm{c}}$ concentrations, and is widely considered to be an independent risk factor for micro- and macrovascular complications $[10,13]$. ADA guidelines state that PPG should be less than $180 \mathrm{mg} / \mathrm{dL} 1-2 \mathrm{~h}$ post-meal [13]. Clinicians should be purposeful in titrating insulin dose to achieve a target fasting glucose, but should also know when to look at the contributions of PPG to the $\mathrm{HbA}_{1 \mathrm{c}}$ levels, with bolus insulin or GLP-1RAs considered logical intensifications [14]. There are useful clinical tools to help the clinician in identifying such patients: one is the Accurate Insulin Decisions website [15], which provides guidelines covering when it is appropriate to consider intensifying a patient's insulin therapy, such as a total daily basal dose at or exceeding 0.5 units $/ \mathrm{kg}$ of basal insulin. Second, the BeAM value (differences between bedtime and morning glucose), which identifies patients 
who need tighter PPG control rather than further increases in their basal insulin doses (when the calculated difference is $45-55 \mathrm{mg} / \mathrm{dL}$ ) [16]. There is a risk that patients who are not correctly identified as needing intensification could continue to have inappropriate "over-basalization" rather than additional therapies.

There are several known perceived barriers to intensification of insulin therapy, including fear of hypoglycemia [17], concerns about weight gain [17], and patient difficulties with adherence, such as when regimen and dosing calculation complexity becomes challenging [17]. With the number of therapeutic options increasing, the wide range of potential combination regimens can be daunting, and this perceived complexity may actually contribute to delays in intensification. There is, therefore, an argument for the development of easy-to-use, well-tolerated therapies combining basal insulin supplementation with a component that can address PPG control while minimizing these barriers.

\section{Pharmacological Logic of Basal Insulin plus GLP-1RA}

The progressive nature of T2D means that, eventually, many T2D patients will need exogenous insulin supplementation to maintain glycemic control $[18,19]$. Exogenous basal insulin is usually titrated to address control of fasting plasma glucose (FPG) [19]. In addition, supplementing endogenous insulin may suppress insulin release from the $\beta$-cell [20] to preserve residual $\beta$-cell function [21], promoting a greater endogenous prandial insulin response. Exogenous insulin can also help preserve $\beta$-cell function; although there are no data on human patients, mouse models have shown that $\beta$-cells can de-differentiate in response to hyperglycemia, with re-differentiation when euglycemia is achieved with exogenous insulin [22].

In healthy individuals, native GLP-1 is a peptide hormone secreted by the gut wall in response to nutrient ingestion, increasing insulin secretion and inhibiting glucagon secretion. GLP-1 also prolongs gastric emptying [23], thereby lowering overall food intake [23], and this was thought to be the reason why therapeutic agents based on GLP-1 resulted in weight loss [23]. However, while this is true for short-acting GLP-1RAs [24], recent findings have demonstrated that for long-acting GLP-1RAs, weight loss is mediated by regulation of appetite signals in the brain [25]. A GLP-1RA will therefore help optimize the prandial insulin response to control PPG, reduce the insulin dose requirement, and mitigate the weight gain associated with insulin therapy. Unlike other therapeutic options, its glucose-lowering action is glucose dependent, thus GLP-1RA achieves these benefits without the risk of hypoglycemia associated with the use of rapid-acting prandial insulins or sulfonylureas. Long-acting GLP-1RAs can lower FPG in addition to simulating prandial insulin response, whereas short-acting GLP-1RAs act primarily to inhibit gastric emptying, thus lowering PPG at the meal that follows dosing [24].

Owing to their different and complementary modes of action, the combination of basal insulin and GLP-1RAs addresses seven of the eight key defects seen in T2D [8, 9]. Insulin decreases lipolysis in the adipocytes, while GLP-1RAs augment insulin secretion, decrease glucagon secretion from the pancreas, and thus reduce hepatic glucose production. GLP-1RAs also improve insulin sensitivity in muscles by promoting weight loss, thus reducing the lipid levels in muscles, and improving muscle sensitivity to insulin [9]. GLP-1RAs supplement any deficient incretin response in the intestine by binding to and activating GLP-1 receptors throughout the body, and reduce appetite signals in the brain. The only defect that insulin/ GLP-1RA combination products do not address is increased glucose reabsorption from the kidney $[8,9]$.

Because of these theoretical benefits, many studies have assessed and demonstrated the clinical feasibility and value of treating patients with GLP-1RAs plus basal insulin. These studies have been subject to a recent systematic review in which the majority of them demonstrated improved glycemic control, without hypoglycemia or weight gain, when GLP-1RA was added to basal insulin therapy [26]. With the 
clinical benefits of this approach well established, a logical progression has been the development of fixed-ratio combination products that simplify the practical use of the regimen for patients. By combining a basal insulin and GLP-1RA in a single injection pen, patients can potentially benefit from a simplified regimen with reduced frequency of injections.

\section{COMBINATION PRODUCTS}

The first fixed-ratio basal insulin/GLP-1RA combination products were approved by the US Food and Drug Administration (FDA) in November $2016[27,28]$. These products were Xultophy $^{\circledR}$ 100/3.6 (IDegLira) and Soliqua ${ }^{\mathrm{TM}}$ 100/33 (IGlarLixi) $[27,28]$. Xultophy ${ }^{\circledR}$ was also approved by the European Medicines Agency (EMA) in September 2014 [29], and Soliqua ${ }^{\circledR}$ was approved by the EMA in January 2017 [30].

\section{IDegLira-Novo Nordisk A/S, Bagsværd, Denmark}

IDegLira is a fixed-ratio combination of insulin degludec (IDeg) and liraglutide, containing 100 units $/ \mathrm{mL}(\mathrm{U} / \mathrm{mL})$ of IDeg and $3.6 \mathrm{mg} / \mathrm{mL}$ of liraglutide in a 3-mL prefilled injection pen [19].

IDeg is a long-acting basal insulin that achieves its protracted action through multihexamer formation in the subcutaneous injection depot [31]. IDeg has a half-life of over $24 \mathrm{~h}$ [32], meaning that with once-daily dosing, a steady state is achieved with little pharmacodynamic variability [31]. This results in a predictably flat and stable glucose-lowering action with a low risk of hypoglycemia compared with insulin glargine 100 units/mL (IGlar U100) $[33,34]$. Recently, IDeg was shown to be superior to IGlar U100 in terms of rates of severe hypoglycemia in the DEVOTE study, rate ratio 0.60 (95\% CI $0.48,0.76$ ), $p<0.001$ for superiority [35]. The DEVOTE study also showed that IDeg was non-inferior to IGlar U100 with regard to incidence rates of major adjudicated cardiovascular events (MACE); hazard ratio 0.91 (95\% CI $0.78,1.06), p<0.001$ for non-inferiority [35].

Liraglutide is a once-daily analogue of human GLP-1 with 97\% amino acid sequence homology to endogenous GLP-1 [36]. Liraglutide reduces both FPG and PPG excursions [17] via its glucose-dependent effects on $\beta$ - and $\alpha$-cell function [17]. Protraction is achieved through self-association as heptamers in the depot, albumin binding in the circulation, and resistance to dipeptidyl peptidase-4 (DPP-4; an enzyme that rapidly degrades endogenous GLP-1), resulting in a half-life of approximately $13 \mathrm{~h}$, which means that a 24 -h action is achieved with once-daily dosing. In the LEADER cardiovascular outcomes trial (CVOT), liraglutide was shown to be superior to placebo when analyzing the incidence rates of MACE; hazard ratio 0.87 (95\% CI 0.78, 0.97), $p<0.001$ for non-inferiority, $p=0.01$ for superiority [37].

\section{IGlarLixi-Sanofi-Aventis, Bridgewater, NJ, USA}

IGlarLixi is a fixed-ratio combination of insulin glargine (IGlar) and lixisenatide, containing $100 \mathrm{U} / \mathrm{mL}$ of IGlar and $33 \mu \mathrm{g} / \mathrm{mL}$ of lixisenatide in a 3-mL prefilled injection pen [28, 38, 39]. Two co-formulations were developed: Pen A, with a ratio of $2 \mathrm{U}$ of IGlar and $1 \mu \mathrm{g}$ of lixisenatide; and Pen $B$, with a ratio of $3 U$ of IGlar and $1 \mu \mathrm{g}$ of lixisenatide [38]. Pen B was approved by the FDA in November 2016 [28]. It is worth noting that the Pen $\mathrm{B}$ used during the LixiLan trials had a dose range 30-60 U, whereas the Pen B approved by the FDA allows a starting dose of $15 \mathrm{U}$.

IGlar U100 is a basal insulin that achieves a protracted action through post-injection precipitation, which retards absorption and results in an action time of approximately $24 \mathrm{~h}$, enabling once-daily dosing in most patients [40-42].

Lixisenatide is a once-daily injectable, synthetic, exendin-derived GLP-1RA for which PPG lowering is brought about mostly through delayed gastric emptying and reduced glucagon release $[38,39]$. Lixisenatide is resistant to DPP-4, binds the GLP-1 receptor with high affinity, but has a half-life of only 2-4 h [43]. This relatively shorter half-life means that in the clinical study program, lixisenatide has been dosed before patients' main meals to gain the maximum benefit. In the ELIXA CVOT, lixisenatide was found to be non-inferior to placebo in terms of risk of MACE [44]. 
These two combination products-IDegLira and IGlarLixi-are both titrated in a similar fashion to a basal insulin, although different titration regimens were used in the clinical development programs. Titration allows a gradual increase in the GLP-1RA dose, thereby enabling the avoidance of nausea, the most common side effect of GLP-1RAs [38]. Healthy eating can also help minimize this side effect and has the benefit of improving glucose further.

\section{Evidence of Clinical Benefit}

The clinical utility of these combination products has been established through a series of phase 3 efficacy and safety trials. No new studies of human or animal subjects have been performed by any of the authors for this article.

For IDegLira, these were the "DUAL" trials, with DUAL I-VI studies published; key results are summarized in Table 1. Direct comparisons of results should not be made across these trials as different patient populations were studied in each. IDegLira was initiated with doses of $10 \mathrm{U}$ (10 U insulin degludec/0.36 mg liraglutide) for DUAL I [19], DUAL IV [45], and DUAL VI [46], and $16 \mathrm{U}$ (16 $\mathrm{U}$ insulin degludec/0.58 mg liraglutide) for DUAL II [17], DUAL III [47], and DUAL V [48]. IDegLira improved glycemic control and mitigated the primary side effects of insulin and GLP-1RA therapy in patients uncontrolled on oral antidiabetic drugs (OADs; DUAL I main trial and extension, DUAL IV, and DUAL VI), basal insulin (DUAL II and DUAL V), or GLP-1RA therapy (DUAL III) [17, 19, 45-48]. IDegLira resulted in significantly greater $\mathrm{HbA}_{1 \mathrm{c}}$ reductions versus either of its mono-components (DUAL I main trial and extension) [19], and superior $\mathrm{HbA}_{1 \mathrm{c}}$ reductions were observed with IDegLira versus IGlar U100 up-titration (DUAL V) [48] and versus unchanged GLP-1RA therapy (DUAL III) [47]. IDegLira was weight-neutral in patients uncontrolled on OADs, resulted in weight loss in those uncontrolled on basal insulin, and weight gain in those uncontrolled on GLP-1RA. Rates of confirmed hypoglycemia ranged between 1.5 and 3.5 events/patient-year of exposure (PYE) in DUAL I-V, with the highest rates being observed in DUAL III and DUAL IV, in which background therapy included sulfonylureas $[17,19,45,47,48]$. Nausea occurred in no more than $4 \%$ of patients receiving IDegLira at any given time in DUAL I-V [17, 19, 45, 47, 48].

IGlarLixi safety and efficacy analyses were previously conducted in the LixiLan-O and LixiLan-L trials [38, 39]. Key results are summarized in Table 2. These two 30-week studies demonstrated superior $\mathrm{HbA}_{1 \mathrm{c}}$ reductions versus lixisenatide in patients uncontrolled on OADs (LixiLan-O) and versus IGlar U100 in patients uncontrolled on basal insulin (LixiLan-L) $[38,39]$. Non-inferior $\mathrm{HbA}_{1 \mathrm{c}}$ reductions with IGlarLixi versus IGlar U100 were also seen in patients uncontrolled on OADs (LixiLan-O) [39]. Change in body weight from baseline to end of trial was $-0.3 \mathrm{~kg}$ and $-0.7 \mathrm{~kg}$ in LixiLan-O and LixiLan-L, respectively, and rates of documented symptomatic hypoglycemia were 1.4 and 3.0 events/patient-year. In terms of gastrointestinal adverse events, nausea occurred in 9.6\% and $10.4 \%$ of patients in the LixiLan-O and LixiLan-L trials, respectively (Table 2) [38, 39].

It is worth noting that direct comparisons between the results of the LixiLan and DUAL studies should not be made because of the different study designs, patient populations, interventions, and definitions used. At the time of writing, no head-to-head studies have been conducted. However, there have been previous comparisons of the individual components. A meta-analysis comparing hypoglycemia rates at equivalent $\mathrm{HbA}_{1 \mathrm{c}}$ values in IDeg and IGlar U100 found similar improvements in $\mathrm{HbA}_{1 \mathrm{c}}$ values with significantly fewer overall confirmed hypoglycemic episodes in favor of IDeg [33]. Meanwhile, liraglutide has been shown to reduce $\mathrm{HbA}_{1 \mathrm{c}}$ to a statistically significantly greater extent versus lixisenatide when added to metformin in a 26-week, head-to-head study, with an estimated treatment difference (ETD) $-0.62 \%$ (95\% CI $-0.8,-0.4), p<0.0001$ [49]. A greater proportion of patients reached either $\mathrm{HbA}_{1 \mathrm{c}}$ less than $7 \% /$ less than or equal to $6.5 \%$ (less than 53/less than or equal to $48 \mathrm{mmol} / \mathrm{mol}$ ) with liraglutide versus lixisenatide $(74.2 \%$ vs. $45.5 \% / 54.6 \%$ vs. $26.2 \%$ respectively, $p<0.0001$ for both) [49]. While liraglutide was associated with a greater reduction in mean 9-point self-measured plasma 


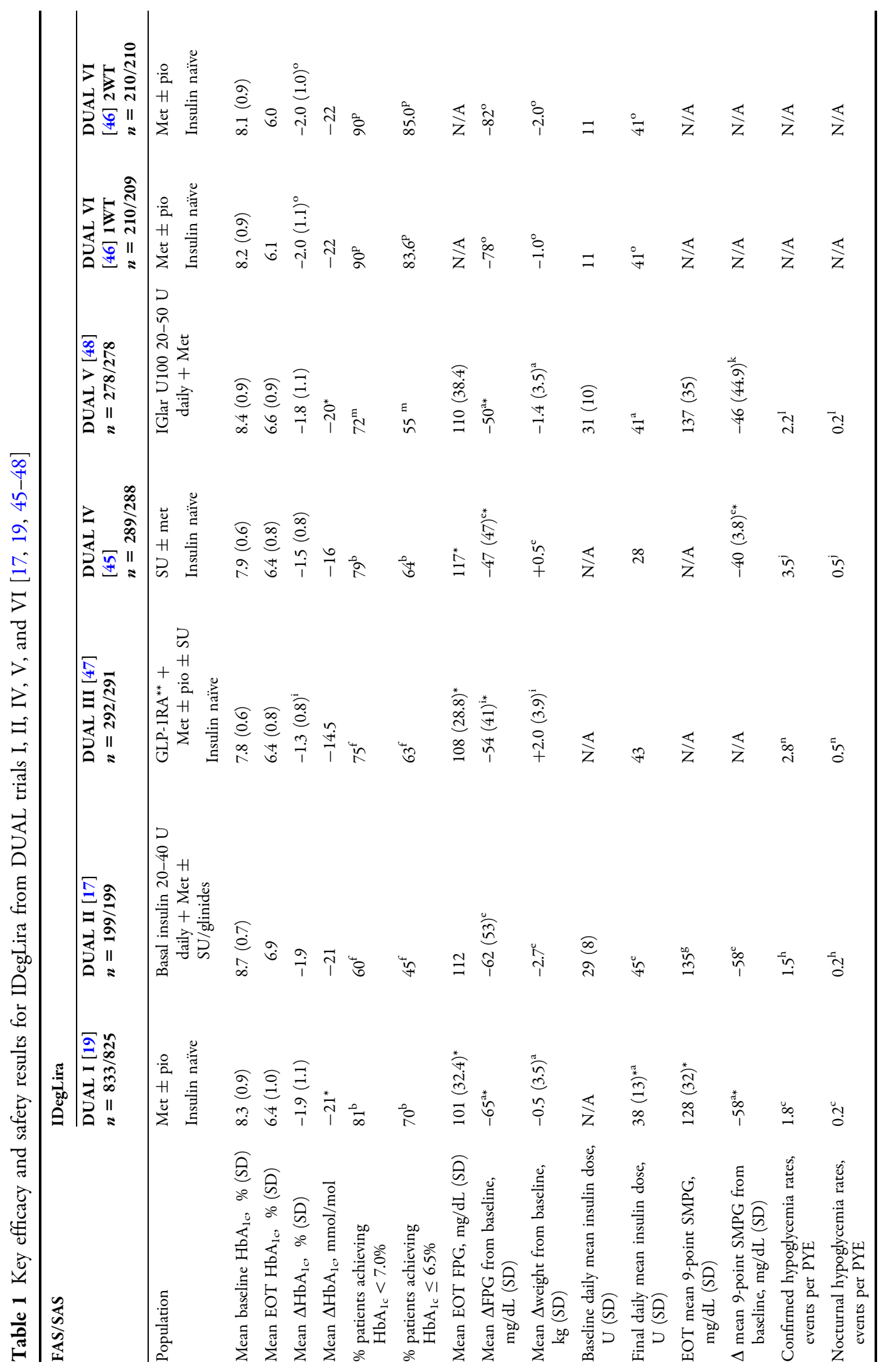




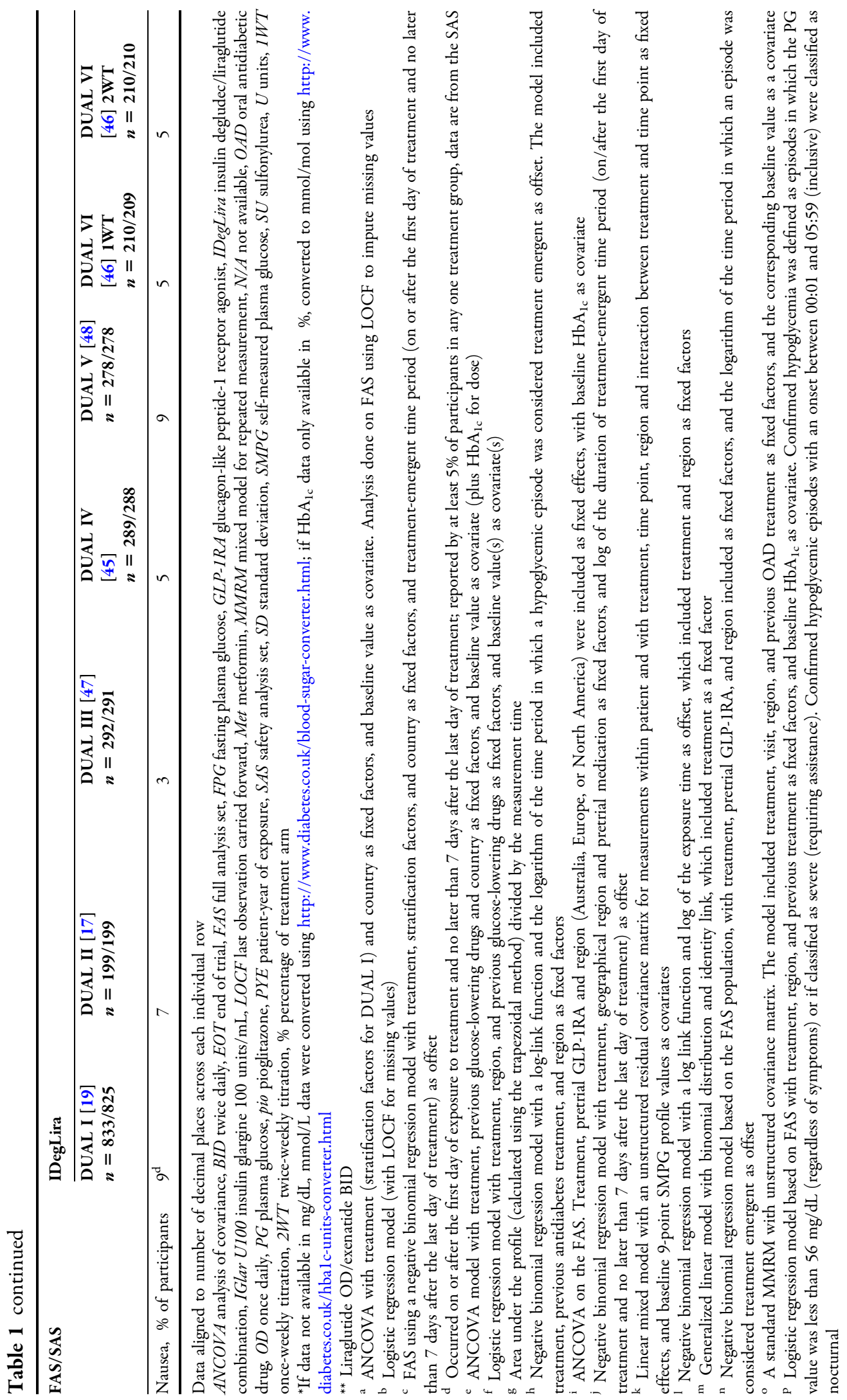


Table 2 Key efficacy and safety results for IGlarLixi from LixiLan-O [39] and LixiLan-L [38]

\begin{tabular}{|c|c|c|}
\hline & \multicolumn{2}{|l|}{ IGlarLixi } \\
\hline & $\begin{array}{l}\text { LixiLan-O [39] } \\
n=468\end{array}$ & $\begin{array}{l}\text { LixiLan-L [38] } \\
n=367\end{array}$ \\
\hline \multirow[t]{2}{*}{ Population } & Met \pm 2nd OAD & \multirow{2}{*}{$\begin{array}{c}\text { Basal insulin } 15-40 \mathrm{U} \\
\text { daily } \pm 1-2 \text { OADs }\end{array}$} \\
\hline & Insulin naïve & \\
\hline \multirow[t]{2}{*}{ Run-in phase } & 4 weeks & 6 weeks \\
\hline & Met & Met + IGlar U100 \\
\hline Baseline $\mathrm{HbA}_{1 \mathrm{c}}$, \% (SD) & $8.1(0.7)$ & $8.1(0.7)$ \\
\hline EOT $\mathrm{HbA}_{1 \mathrm{c}}, \%(\mathrm{SD})$ & $6.5(0.8)^{\mathrm{a}}$ & $6.9(0.9)^{\mathrm{a}}$ \\
\hline Mean $\Delta \mathrm{HbA}_{1 \mathrm{c}}, \%(\mathrm{SD})$ & $-1.6(0.04)$ & $-1.1(0.06)$ \\
\hline Mean $\Delta \mathrm{HbA}_{1 \mathrm{c}}, \mathrm{mmol} / \mathrm{mol}$ & -17 & -7 \\
\hline$\%$ patients achieving $\mathrm{HbA}_{1 \mathrm{c}}<7.0 \%$ & $74^{\mathrm{b}}$ & $55^{\mathrm{b}}$ \\
\hline$\%$ patients achieving $\mathrm{HbA}_{1 \mathrm{c}} \leq 6.5 \%$ & $56^{\mathrm{b}}$ & $34^{\mathrm{b}}$ \\
\hline EOT FPG, mg/dL (SD) & $113.4(6.3)^{*}$ & $122(41)$ \\
\hline$\Delta \mathrm{FPG}$ from baseline, $\mathrm{mg} / \mathrm{dL}(\mathrm{SD})$ & $-63.0(1.8)^{b_{*}}$ & $-6(3)^{b}$ \\
\hline$\Delta$ weight from baseline, $\mathrm{kg}(\mathrm{SD})$ & $-0.3(0.2)^{\mathrm{b}}$ & $-0.7(0.2)^{\mathrm{b}}$ \\
\hline Baseline daily mean insulin dose, $U$ (SD) & $\mathrm{N} / \mathrm{A}$ & $27(8)$ \\
\hline Final daily insulin dose, $\mathrm{U}(\mathrm{SD})$ & $40(15)^{b}$ & $47(13)^{b}$ \\
\hline EOT mean 7-point SMPG, mg/dL (SD) & $\mathrm{N} / \mathrm{A}$ & $140(31)$ \\
\hline$\Delta$ mean 7-point SMPG from baseline, $\mathrm{mg} / \mathrm{dL}(\mathrm{SD})$ & $-0.69^{\mathrm{b} *}$ & $-27(2)^{b}$ \\
\hline$\Delta$ 2-h postprandial glucose from baseline, $\mathrm{mg} / \mathrm{dL}$ & $-102.6(3.6)^{d_{*}}$ & $-85(6)^{\mathrm{d}}$ \\
\hline Confirmed hypoglycemia rates, events per PYE & $1.4^{\mathrm{c}}$ & $3.03^{\mathrm{c}}$ \\
\hline Nocturnal hypoglycemia rates, events per PYE & $\mathrm{N} / \mathrm{A}$ & $\mathrm{N} / \mathrm{A}$ \\
\hline Nausea, \% of participants & 9.6 & 10.4 \\
\hline
\end{tabular}

ANCOVA analysis of covariance, EOT end of trial, FAS full analysis set, FPG fasting plasma glucose, IGlar U100 insulin glargine 100 units/mL, IGlarLixi insulin glargine/lixisenatide combination, Met metformin, $N / A$ not available, OAD oral antidiabetic drug, $P G$ plasma glucose, $P Y E$ patient-year of exposure, $S A S$ safety analysis set, $S D$ standard deviation, $S M P G$ self-measured plasma glucose, $U$ units, $\%$ percentage of treatment arm

${ }^{*}$ If data not available in $\mathrm{mg} / \mathrm{dL}, \mathrm{mmol} / \mathrm{L}$ data were converted using http://www.diabetes.co.uk/blood-sugar-converter.html

${ }^{a}$ Mixed-effect model with repeated measures with treatment groups, randomization strata of $\mathrm{HbA}_{1 \mathrm{c}}(<8.0 \%, \geq 8.0 \%)$, randomization strata of second oral glucose-lowering therapy use at screening, visit, treatment-by-visit interaction, and country as fixed effects, and baseline outcome measure value by visit as a covariate

b A mixed-effect model with repeated measures with treatment groups, randomization strata of $\mathrm{HbA}_{1 \mathrm{c}}(<8.0 \%, \geq 8.0 \%)$, randomization strata of second oral glucose-lowering therapy use at screening, visit, treatment-by-visit interaction, and country as fixed effects and baseline outcome, and Cochran-Mantel-Haenszel method stratified by randomization strata ${ }^{c}$ Number of events divided by total PYE. PYE calculated as time from the first to the last injection of investigational drug plus 1 day; documented symptomatic hypoglycemia = typical symptoms of hypoglycemia accompanied by a measured PG concentration of less than $70 \mathrm{mg} / \mathrm{dL}(3.9 \mathrm{mmol} / \mathrm{L})$ or $60 \mathrm{mg} / \mathrm{dL}(3.3 \mathrm{mmol} / \mathrm{L})$

d ANCOVA model with treatment groups, randomization strata of $\mathrm{HbA}_{1 \mathrm{c}}(<8.0 \%, \geq 8.0 \%)$, randomization strata of second oral glucose-lowering therapy use at screening, and country as fixed effects, and baseline 2-h postprandial PG excursion value as a covariate. $N$ is number of patients, where FAS and SAS are not detailed 
glucose (SMPG; $p<0.0001$ ), lixisenatide was associated with a smaller PPG excursion versus liraglutide, but only for the first meal eaten after the daily injection $(p<0.05)$, with no statistical difference between the two treatments across all meals [49]. Body weight reductions and adverse events, including hypoglycemic events, were similar for both GLP-1RAs [49]. In an 8-week trial in 2015, Meier et al. demonstrated comparable end-of-trial $\mathrm{HbA}_{1 \mathrm{c}}$ values for lixisenatide $20 \mu \mathrm{g} \quad(6.2 \% \pm 0.4) \quad$ compared with liraglutide $1.2 \mathrm{mg}(6.1 \% \pm 0.3)$ and liraglutide $1.8 \mathrm{mg}(6.1 \% \pm 0.3)$ [50]. Marginal mean treatment differences were not significant with lixisenatide $20 \mu \mathrm{g}$ versus liraglutide $1.2 \mathrm{mg}$ $[-0.1 \%(95 \% \mathrm{CI}-0.2,0.03), p=0.17]$; however, liraglutide $1.8 \mathrm{mg}$ had a significant marginal mean treatment difference versus lixisenatide $20 \mu \mathrm{g}[-0.2 \%(95 \% \mathrm{CI}-0.3,-0.05), p=0.007]$ [50]. Lixisenatide produced a greater reduction in the incremental area under the curve (AUC) between time points 00:30 and 04:30 (AUC $\mathrm{PPG}_{00: 30-04: 30 \mathrm{~h}}$ ) compared with liraglutide doses of 1.2 and $1.8 \mathrm{mg}$ (ETD $-108.3 \mathrm{~h} \mathrm{mg} / \mathrm{dL}$ and $-83.0 \mathrm{~h} \mathrm{mg} / \mathrm{dL}$, respectively; both $p<0.001$ ) [50]. There was no statistically significant difference in FPG reductions between lixisenatide and either dose of liraglutide [50]. In this study, the most common adverse events reported were nausea and symptomatic hypoglycemia. Lixisenatide $20 \mu \mathrm{g}$ and liraglutide $1.2 \mathrm{mg}$ had similar proportions of patients reporting nausea, $18.8 \%$ and $17.0 \%$ respectively, while $23.4 \%$ of patients on liraglutide $1.8 \mathrm{mg}$ reported nausea [50]. A greater proportion of patients on lixisenatide $20 \mu \mathrm{g}$ reported symptomatic hypoglycemia than patients on liraglutide $1.2 \mathrm{mg}$ or $1.8 \mathrm{mg}(29.2 \%$, $19.1 \%$, and $21.3 \%$ of patients, respectively) [50].

\section{PRACTICALITIES (WITH WHOM, HOW, AND WHEN DO I USE COMBINATION PRODUCTS?)}

\section{Target Population}

Patients who would benefit from intensification include those in whom $\mathrm{HbA}_{1 \mathrm{c}}$ values remain high despite an acceptable FPG (although this was only a requirement in the LixiLan trials, not the DUAL trials), those with glucose variability in the morning, and those whose total daily basal insulin dose is greater than 0.5 units/ $\mathrm{kg} /$ day. $\mathrm{HbA}_{1 \mathrm{c}}$ values do not give an accurate picture of glycemic variability, and patients can be at goal for FPG levels while still having $\mathrm{HbA}_{1 \mathrm{c}}$ above target. Previous treatment is also a factor as those patients unable to achieve glycemic control on GLP-1RA- or basal insulin-based regimens, especially when PPG increments are limiting $\mathrm{HbA}_{1 \mathrm{c}}$ target achievement, could benefit from switching. In addition, there may be patients who will benefit from the relative simplicity of these products; a patient on a basal-bolus insulin regimen could potentially see their weekly number of total injections decrease from 28 to 7 if switched to a fixedratio combination insulin/GLP-1RA product.

Another target population would be one where further intensification of therapy is being delayed because of fears surrounding potential weight gain and hypoglycemic episodes. A regimen that does not increase the daily number of basal insulin injections, while still promoting weight loss and reduced frequencies of hypoglycemic episodes, could be more acceptable, thus improving adherence. This is supported by findings in DUAL V, where the patient-reported outcomes (PROs) questionnaire (i.e., Treatment-Related Impact Measure For Diabetes, or TRIM-D) showed an improvement in overall score for IDegLira compared with IGlar U100, mostly because of the large differences in scores in diabetes management, ETD 7.2 (95\% CI 4.2, $10.2), p<0.001$, and treatment burden, ETD 3.7 (95\% CI $0.7,6.8), p=0.017$ [48]. These outcomes were not reported in the LixiLan-L and LixiLan-O trials, although IGlarLixi is also injected once a day, so one might assume that similar benefits would be felt. The aforementioned benefits are likely to make IDegLira and IGlarLixi, which target several physiological defects of T2D, more attractive options to patients, thereby tackling clinical inertia with insulin intensification. This is important because the earlier in the disease trajectory they are introduced, the greater impact they will have on slowing $\beta$-cell deterioration [51, 52]. However, it is worth noting that while both 
products are approved for use in the EU in patients with inadequate glycemic control on OADs $[29,30]$, in the USA both products are only licensed for use in patients with inadequate glycemic control on basal insulin or their respective GLP-1RA mono-components [27, 28].

It is important to acknowledge, however, that while most recent official diabetes treatment guidelines address the mono-components of IDegLira and IGlarLixi, they do not yet specifically cover fixed-ratio combination products [53]. The overall cost of the fixed-ratio combination products should also be taken into account when making the decision to commence a patient on a new or intensified therapy. These medications are expensive; therefore, the insurance status of US patients should be taken into account.

\section{How to Use}

IDegLira is given by once-daily subcutaneous injection, with the injection ideally being administered consistently at the same time of day (which can vary from patient to patient), with or without food [19, 27]. Injection sites should be rotated between the thigh, upper arm, and abdomen [27]. The pens are prefilled for single-patient use only. The product is contraindicated in the following patients: those with a personal or family history of medullary thyroid carcinoma, because of its liraglutide component; those with multiple endocrine neoplasia syndrome type 2 ; those experiencing hypoglycemia episodes; or those with hypersensitivities to IDegLira, IDeg, or liraglutide [27].

The recommended initial dosing of IDegLira is $16 \mathrm{U}$, which delivers $16 \mathrm{U}$ IDeg and $0.58 \mathrm{mg}$ liraglutide [27]. The maximum dose is $50 \mathrm{U}$, which delivers $50 \mathrm{U}$ IDeg $+1.8 \mathrm{mg}$ liraglutide $[19,27]$, the maximum approved dose of liraglutide for T2D. The dose should be titrated according to the mean of three or four consecutive prebreakfast SMPG results using the algorithm shown in Table 3, and according to the individual patient's glycemic target range. It is important to note that maximum dose is not required for efficacy.
Table 3 Titration algorithm for combination products

\begin{tabular}{|c|c|}
\hline $\begin{array}{l}\text { Mean fasting } \\
\text { SMPG }\end{array}$ & Dosage adjustment \\
\hline \multicolumn{2}{|l|}{ IDegLira } \\
\hline $\begin{array}{l}\text { Above target } \\
\text { range }\end{array}$ & $\begin{array}{l}+2 \mathrm{U}(2 \mathrm{U} \text { IDeg and } 0.072 \mathrm{mg} \\
\quad \text { liraglutide })\end{array}$ \\
\hline $\begin{array}{l}\text { Within target } \\
\text { range }\end{array}$ & No adjustment \\
\hline $\begin{array}{l}\text { Below target } \\
\text { range }\end{array}$ & $\begin{array}{l}-2 \mathrm{U} \text { (2 U IDeg and } 0.072 \mathrm{mg} \\
\text { liraglutide) }\end{array}$ \\
\hline \multicolumn{2}{|l|}{ IGlarLixi } \\
\hline $\begin{array}{l}\text { Above target } \\
\text { range }\end{array}$ & $\begin{array}{l}+2 \mathrm{U}(2 \mathrm{U} \text { IGlar } \mathrm{U} 100 \text { and } \\
0.66 \mu \mathrm{g} \text { lixisenatide) to }+4 \mathrm{U} \\
\quad(4 \mathrm{U} \text { IGlar U100 and } 1.32 \mu \mathrm{g} \\
\text { lixisenatide) }\end{array}$ \\
\hline $\begin{array}{l}\text { Within target } \\
\text { range }\end{array}$ & No adjustment \\
\hline $\begin{array}{l}\text { Below target } \\
\text { range }\end{array}$ & $\begin{array}{l}-2 \mathrm{U}(2 \mathrm{U} \text { IGlar } \mathrm{U} 100 \text { and } 0.66 \mu \mathrm{g} \\
\text { lixisenatide) to }-4 \mathrm{U} \text { ( } 4 \mathrm{U} \text { IGlar U100 } \\
\text { and } 1.32 \mu \mathrm{g} \text { lixisenatide) }\end{array}$ \\
\hline
\end{tabular}

IDeg insulin degludec, IDegLira insulin degludec/liraglutide combination, IGlarLixi insulin glargine/lixisenatide combination, IGlar U100 insulin glargine 100 units/mL, $S M P G$ self-measured plasma glucose, $U$ units

The most common side effects occurring in more than $5 \%$ of patients treated with IDegLira include nasopharyngitis, headache, nausea, diarrhea, raised lipase, and upper respiratory tract infections [27]. If patients consistently require doses under $16 \mathrm{U}$ or over $50 \mathrm{U}$ of IDegLira, then switching to alternative therapies should be considered. There are very few significant drug interactions, details of which can be found in the Highlights of Prescribing Information [27].

IGlarLixi is given by once-daily subcutaneous injection [38, 39], with the injection being administered within $1 \mathrm{~h}$ of the first meal of the day [28]. The pen is prefilled for singlepatient use only. Injection sites should be rotated between the thigh, upper arm, and abdomen [28]. IGlarLixi is contraindicated in patients experiencing hypoglycemia episodes, or those with hypersensitivities to IGlarLixi, 
IGlar U100, or lixisenatide [28]. There are no thyroid-related contraindications with products containing lixisenatide, unlike liraglutide. Antibiotics, certain analgesics, or other medications that are particularly dependent on threshold concentrations for efficacy, or for which a delay in effect is undesirable, should be administered at least $1 \mathrm{~h}$ before or $11 \mathrm{~h}$ after IGlarLixi injection.

Other basal insulin or GLP-1RA therapies should be discontinued before initiating IGlarLixi. The recommended initial dosing of IGlarLixi for patients previously uncontrolled on lixisenatide or on less than $30 \mathrm{U}$ basal insulin is $15 \mathrm{U}$, which delivers $15 \mathrm{U}$ IGlar and $5 \mu \mathrm{g}$ lixisenatide, and for patients previously uncontrolled with 30-60 U of basal insulin, the recommended starting dose of IGlarLixi is $30 \mathrm{U}$, which delivers $30 \mathrm{U}$ IGlar and $10 \mu \mathrm{g}$ lixisenatide [28]. The maximum dose is $60 \mathrm{U}$ IGlar $+20 \mu$ g lixisenatide [28]. The dose should be titrated once a week using the algorithm shown in Table 3, according to the individual patient's glycemic target range.

IGlarLixi should be administered up to $1 \mathrm{~h}$ before the first meal daily, although the maximum dose is not required for efficacy. The most common side effects include nausea, nasopharyngitis, diarrhea, upper respiratory tract infection, and headache [28]. If patients consistently require doses of IGlarLixi under $15 \mathrm{U}$ or over $60 \mathrm{U}$, switching to alternative therapies should be considered.

There are few significant drug interactions, details of which can be found in the Highlights of Prescribing Information [28].

\section{Storage Information}

Both IDegLira and IGlarLixi should be stored in a refrigerator at $36-46^{\circ} \mathrm{F}\left(2-8{ }^{\circ} \mathrm{C}\right)$ before use, and should not be frozen. After the first injection, IDegLira can be stored either at room temperature $\left(59-86^{\circ} \mathrm{F} ; 15-30^{\circ} \mathrm{C}\right)$ or in the same refrigerator as before first use for 21 days, away from direct heat or light. Each pen should be used for a maximum of 21 days [27]. After the first injection, IGlarLixi should be stored at room temperature (below $86^{\circ} \mathrm{F} ; 30^{\circ} \mathrm{C}$ ) for
14 days, away from direct light. The pen should be discarded 14 days after the first use [28].

\section{Advice for Demonstrating Injection Technique}

Many patients are intimidated by the prospect of initiating or changing injection therapy, so they often welcome a practical demonstration by their diabetes healthcare provider. Given the titration methods used for IDegLira and IGlarLixi, a demonstration will be especially beneficial if the patient has not used a basal insulin before. Educational videos demonstrating injection techniques can be found online. A checklist of items to explain or show to the patient may also be helpful, and can be found in the Supplementary Material.

\section{CONCLUSIONS}

Type 2 diabetes is a progressive, multi-system disease that affects a large proportion of the global population. Because of its complex pathophysiology, a combination of different medications may often be required to achieve glycemic control, and fixed-ratio combination products allow such therapies to be given in simple regimens. Basal insulin/GLP-1RA fixed-ratio combination products can help in this respect by addressing seven of the eight key defects found in advanced T2D [7, 8]. Compared with basal insulin, insulin/GLP-1RA fixed-ratio combinations are superior at reducing $\mathrm{HbA}_{1 \mathrm{c}}[17,38,47]$, with the added advantage of weight neutrality or weight loss rather than weight gain, as well as reduced hypoglycemia rates, and reduced insulin-dose requirement with IDegLira. These fixed-ratio products are a relatively new addition to our armamentarium and their clinical scope is still under investigation. However, the combination of basal insulin and GLP-1RAs is well studied [54] and makes pharmacological sense. Clinical trial data of these products highlight the great potential of these agents, not merely of their efficacy and safety but also their ease of use and decreased injection burden for patients. 


\section{ACKNOWLEDGEMENTS}

Support for the preparation of this article, including the article processing charges, was funded by Novo Nordisk Inc., Plainsboro, NJ, USA. Virginia Valentine, Jennifer Goldman, and Jay H. Shubrook made substantial contributions to the design of the article; participated in drafting the article or revising it critically for important intellectual content; and gave final approval for the version to be submitted for publication. All authors meet the International Committee of Medical Journal Editors (ICMJE) criteria for authorship for this manuscript, take responsibility for the integrity of the work as a whole, and have given final approval for the version to be published.

Medical writing and submission support were provided by Victoria Stone and Daria Renshaw of Watermeadow Medical, an Ashfield company, part of UDG Healthcare plc. This support was funded by Novo Nordisk Inc., Plainsboro, NJ, USA. Novo Nordisk reviewed this article for medical accuracy only.

Funding. Novo Nordisk Inc.

Disclosures. Virginia Valentine has received honoraria from, and acts as a consultant for, AstraZeneca, Lilly Diabetes, and Novo Nordisk. Jennifer Goldman has appeared on speakers' bureaus for Novo Nordisk and Sanofi, and is a consultant for Becton-Dickinson. Jay H. Shubrook has received research grant support from Sanofi, Takeda, Lilly Diabetes, and AstraZeneca, and acts as a consultant for Lilly Diabetes and Novo Nordisk.

Compliance with Ethics Guidelines. This article is based on previously conducted studies and does not involve any new studies of human or animal subjects performed by any of the authors.

Data Availability. Data sharing is not applicable to this article as no datasets were generated or analyzed during the current study.

Open Access. This article is distributed under the terms of the Creative Commons
Attribution-NonCommercial 4.0 International License (http://creativecommons.org/licenses/ by-nc/4.0/), which permits any noncommercial use, distribution, and reproduction in any medium, provided you give appropriate credit to the original author(s) and the source, provide a link to the Creative Commons license, and indicate if changes were made.

\section{REFERENCES}

1. Gallwitz B. The future of combination therapies of insulin with a glucagon-like peptide-1 receptor agonists in type 2 diabetes-is it advantageous? Eur Endocrinol. 2014;10:98.

2. Cornell S. Key considerations in pharmacotherapy for type 2 diabetes mellitus: a multiple target organ approach. J Clin Pharm Ther. 2011;37:254-9.

3. Levin P. Practical combination therapy based on pathophysiology of type 2 diabetes. Diabetes Metab Syndr Obes. 2016;9:355-69.

4. Bener A, Al-Hamaq AO, Kurtulus EM, Abdullatef $\mathrm{WK}$, Zirie $\mathrm{M}$. The role of vitamin $\mathrm{D}$, obesity and physical exercise in regulation of glycemia in type 2 diabetes mellitus patients. Diabetes Metab Syndr. 2016;10:198-204.

5. International Diabetes Federation. IDF diabetes atlas 7th edition. 2015. http://www.diabetesatlas. org/. Accessed 10 Nov 2016.

6. American Diabetes Association. Economic costs of diabetes in the US in 2012. Diabetes Care. 2013;36:1033-46.

7. Russo GT, Giorda CB, Cercone S, Nicolucci A, Cucinotta D, BetaDecline Study Group. Factors associated with beta-cell dysfunction in type 2 diabetes: the BETADECLINE study. PLOS One. 2014;9:e109702.

8. DeFronzo RA. Banting lecture. From the triumvirate to the ominous octet: a new paradigm for the treatment of type 2 diabetes mellitus. Diabetes. 2009;58:773-95.

9. DeFronzo R, Eldor R, Abdul-Ghani M. Pathophysiologic approach to therapy in patients with newly diagnosed type 2 diabetes. Diabetes Care. 2013;36(Suppl 2):S127-38.

10. Gallwitz B. Implications of postprandial glucose and weight control in people with type 2 diabetes: understanding and implementing the International 
Diabetes Federation guidelines. Diabetes Care. 2009;32(Suppl 2):S322-5.

11. Dale J, Martin S, Gadsby R. Insulin initiation in primary care for patients with type 2 diabetes: 3 -year follow-up study. Prim Care Diabetes. 2010;4:85-9.

12. Wu N, Aagren M, Boulanger L, Friedman M, Wilkey $\mathrm{K}$. Assessing achievement and maintenance of glycemic control by patients initiating basal insulin. Curr Med Res Opin. 2012;28:1647-56.

13. American Diabetes Association. Standards of medical care in diabetes-2017: summary of revisions. Diabetes Care. 2017;40(Suppl 1):S4-5.

14. Inzucchi SE, Bergenstal RM, Buse JB, et al. Management of hyperglycemia in type 2 diabetes: a patient-centered approach: update to a position statement of the American Diabetes Association and the European Association for the Study of Diabetes. Diabetes Care. 2015;38:140-9.

15. Endocrine Society. Deciding whether to transition your patient to mealtime insulin. 2017. Accurate Insulin Decision. http://www.accurateinsulin.org/ for-doctors/deciding-whether-to-transition-yourpatient-to-mealtime-insulin/. Accessed 9 Feb 2017.

16. Zisman A, Morales F, Stewart J, Stuhr A, Vlajnic A, Zhou R. BeAM value: an indicator of the need to initiate and intensify prandial therapy in patients with type 2 diabetes mellitus receiving basal insulin. BMJ Open Diabetes Res Care. 2016;4:e000171.

17. Buse J, Visbøll T, Thurman J, et al. Contribution of liraglutide in the fixed-ratio combination of insulin degludec and liraglutide (IDegLira). Diabetes Care. 2014;37:2926-33.

18. Lim EL, Hollingsworth KG, Aribisala BS, Chen MJ, Mathers JC, Taylor R. Reversal of type 2 diabetes: normalization of beta cell function in association with decreased pancreas and liver triacylglycerol. Diabetologia. 2011;54:2506-14.

19. Gough S, Bode B, Woo V, et al. Efficacy and Safety of a fixed-ratio combination of insulin degludec and liraglutide (IDegLira) compared with its components given alone: results of a phase 3, open-label, randomised, 26-week, treat-to-target trial in insulin-naïve patients with type 2 diabetes. Lancet Diabetes Endocrinol. 2014;2:885-93.

20. Jackson RL, Boyd JD, Smith TE. Stabilization of the diabetic child. Am J Dis Child. 1940;59:332-41.

21. Weir GC, Bonner-Weir S. Five stages of evolving beta-cell dysfunction during progression to diabetes. Diabetes. 2004;53(Suppl 3):S16-21.
22. Wang Z, York N, Nichols C, Remedi M. Pancreatic $\beta$ cell dedifferentiation in diabetes and redifferentiation following insulin therapy. Cell Metab. 2014;19:872-82.

23. Garber A. Long-acting glucagon-like peptide 1 receptor agonists: a review of their efficacy and tolerability. Diabetes Care. 2011;34(Suppl 2):S279-84.

24. Meier JJ. GLP-1 receptor agonists for individualized treatment of type 2 diabetes mellitus. Nat Rev Endocrinol. 2012;8:728-42.

25. van Can J, Sloth B, Jensen B, Flint A, Blaak EE, Saris WHM. Effects of the once-daily GLP-1 analog liraglutide on gastric emptying, glycemic parameters, appetite and energy metabolism in obese, non-diabetic adults. Int J Obes (Lond). 2014;38:784-93.

26. Balena R, Hensley I, Miller S, Barnett A. Combination therapy with GLP-1 receptor agonists and basal insulin: a systematic review of the literature. Diabetes Obes Metab. 2012;15:485-502.

27. Novo Nordisk. Highlights of prescribing information Xultophy 100/3.6. 2017. http://www.accessdata.fda. gov/drugsatfda_docs/label/2016/208583s000lbl.pdf. Accessed 11 Jan 2017.

28. Sanofi-Aventis. Highlights of prescribing information Soliqua 100/33. 2017. http://www.accessdata. fda.gov/drugsatfda_docs/label/2016/208673s000lbl. pdf. Accessed 11 Jan 2017.

29. European Medicines Agency. EPAR summary for the public. Xultophy. 2015. http://www.ema.europa.eu/ docs/en_GB/document_library/EPAR_-_Summary_ for_the_public/human/002647/WC500177660.pdf. Accessed 1 June 2017.

30. European Medicines Agency. EPAR summary for the public. Soliqua. 2017. http://www.ema.europa.eu/ docs/en_GB/document_library/EPAR_-_Summary_ for_the_public/human/004243/WC500224677.pdf. Accessed 1 June 2017.

31. Steensgaard DB, Schuckebier G, Strauss HM, et al. Ligand-controlled assembly of hexamers, dihexamers, and linear multihexamer structures by the engineered acylated insulin degludec. Biochemistry. 2013;52:295-309.

32. Heise T, Hövelmann U, Nosek L, Hermanski L, Bøttcher SG, Haahr H. Comparison of the pharmacokinetic and pharmacodynamic profiles of insulin degludec and insulin glargine. Expert Opin Drug Metab Toxicol. 2015;11:1193-201.

33. Ratner R, Gough S, Mathieu C, et al. Hypoglycaemia risk with insulin degludec compared with insulin glargine in type 2 and type 1 diabetes: a 
pre-planned meta-analysis of phase 3 trials. Diabetes Obes Metab. 2012;15:175-84.

34. Wysham C, Bhargava A, Chaykin LB, et al. Effect of Insulin Degludec vs Insulin Glargine U100 on Hypoglycemia in Patients With Type 2 Diabetes: The SWITCH 2 Randomized Clinical Trial. JAMA. 2017;318:45-56.

35. Marso SP, McGuire DK, Zinman B, et al. Efficacy and safety of degludec versus glargine in type 2 diabetes. N Engl J Med. 2017. doi:10.1056/ NEJMoa1615692.

36. Vilsbøll T. Liraglutide: a human GLP-1 analog for type 2 diabetes. Therapy. 2009;6:199-207.

37. Marso S, Daniels G, Brown-Frandsen K, et al. Liraglutide and cardiovascular outcomes in type 2 diabetes. N Engl J Med. 2016;375:311-22.

38. Aroda V, Rosenstock J, Wysham C, et al. Efficacy and safety of LixiLan, a titratable fixed-ratio combination of insulin glargine plus lixisenatide in type 2 diabetes inadequately controlled on basal insulin and metformin. The LixiLan-L randomized trial. Diabetes Care. 2016;39:1972-80.

39. Rosenstock J, Aronson R, Grunberger G, et al. Benefits of LixiLan, a titratable fixed-ratio combination of insulin glargine plus Lixisenatide, versus insulin glargine and lixisenatide monocomponents in type 2 diabetes inadequately controlled on oral agents: the LixiLan-O randomized trial. Diabetes Care. 2016;39:2026-35.

40. Seipke G, Geisen K, Neubauer H-P, Pittius C, Rosskamp R, Schwabe D. New insulin preparations with prolonged action profiles: a21-modified arginine insulins. Diabetologia. 1992;35(Suppl 1):A4.

41. Rosenstock J, Park G, Zimmerman J. US insulin glargine (HOE 901) type 1 diabetes investigator group. Basal insulin glargine (HOE 901) versus NPH insulin in patients with type 1 diabetes on multiple daily insulin regimens. Diabetes Care. 2000;23:1137-42.

42. Owens D. Insulin preparations with prolonged effect. Diabetes Technol Ther. 2011;13(Suppl. 1):S5-14.

43. Distiller L, Ruus P. Pharmacokinetics and pharmacodynamics of GLP-1 agonist AVE0010 in type 2 diabetes patients. Diabetes. 2008;57(Suppl 1):520-P (abstract).

44. Pfeffer M, Claggett B, Diaz R, et al. Lixisenatide in patients with type 2 diabetes and acute coronary syndrome. N Engl J Med. 2015;373:2247-57.

45. Rodbard H, Bode B, Harris S, et al. Safety and efficacy of insulin degludec/liraglutide (IDegLira) added to sulphonylurea alone or to sulphonylurea and metformin in insulin-naïve people with type 2 diabetes: the DUAL IV trial. Diabet Med. 2017;34:189-96.

46. Harris SB, Kocsis G, Prager R, et al. Safety and efficacy of IDegLira titrated once weekly versus twice weekly in patients with type 2 diabetes uncontrolled on oral antidiabetic drugs: Dual VI randomized clinical trial. Diabetes Obes Metab. 2017;19:858-65.

47. Linjawi S, Bode B, Chaykin L, et al. The efficacy of IDegLira (insulin degludec/liraglutide combination) in adults with type 2 diabetes inadequately controlled with a GLP-1 receptor agonist and oral therapy: DUAL III randomized clinical trial. Diabetes Ther. 2017;8:101-14.

48. Lingvay I, Manghi F, García-Hernández P, et al. Effect of insulin glargine up-titration vs insulin degludec/liraglutide on glycated hemoglobin levels in patients with uncontrolled type 2 diabetes. The DUAL V randomized clinical trial. JAMA. 2016;315:898-907.

49. Nauck M, Rizzo M, Johnson A, Bosch-Traberg H, Madsen J, Cariou B. Once-daily liraglutide Versus lixisenatide as add-on to metformin in type 2 diabetes: a 26-week randomized controlled clinical trial. Diabetes Care. 2016;39:1501-9.

50. Meier JJ, Rosenstock J, Hincelin-Méry A, et al. Contrasting effects of lixisenatide and liraglutide on postprandial glycemic control, gastric emptying, and safety parameters in patients with type 2 diabetes on optimized insulin glargine with or without metformin: a randomized, open-label trial. Diabetes Care. 2015;38:1263-73.

51. DeFronzo RA, Eldor R, Abdul-Ghani M. Pathophysiologic approach to therapy in patients with newly diagnosed type 2 diabetes. Diabetes Care. 2013;36:S127-38.

52. Raz I. Guideline approach to therapy in patients with newly diagnosed type 2 diabetes. Diabetes Care. 2013;36(Suppl):S139-44.

53. Garber A, Abrahamson M, Barzilay J, et al. Consensus statement by the American Association of Clinical Endocrinologists and American College of Endocrinology on the comprehensive type 2 diabetes management algorithm-2017 executive summary. Endocr Pract. 2017;23:207-38.

54. Cimmaruta D, Maiorino MI, Scavone C, et al. Efficacy and safety of insulin-GLP-1 receptor agonists combination in type 2 diabetes mellitus: a systematic review. Expert Opin Drug Saf. 2016;15(Suppl. 2):77-83. 